\title{
School-Based Life Skills Program to Reduce Psychosocial Barriers to Achieving Child Nutrition and Obesity Prevention
}

\author{
Martha Givaudan*, Marco Barriga, Georgina García, Itzel Valdez, Cory Silver \\ Mexican Institute of Family and Population Research (IMIFAP), Mexico City, Mexico \\ Email address: \\ martha@imifap.org.mx (M. Givaudan), marco@imifap.org.mx (M. Barriga), gina@imifap.org.mx (G. García), \\ itzel@imifap.org.mx (I. Valdez), csilver@jhu.edu (C. Silver) \\ ${ }^{*}$ Corresponding author
}

\section{To cite this article:}

Martha Givaudan, Marco Barriga, Georgina García, Itzel Valdez, Cory Silver. School-Based Life Skills Program to Reduce Psychosocial Barriers to Achieving Child Nutrition and Obesity Prevention. American Journal of Applied Psychology. Vol. 9, No. 5, 2020 , pp. 131-139. doi: 10.11648/j.ajap.20200905.11

Received: August 24, 2020; Accepted: September 9, 2020; Published: September 21, 2020

\begin{abstract}
Childhood obesity is a critical and growing public health crisis across the world, with implications ranging from the development of noncommunicable diseases such as diabetes, which has been especially revelant in recent months due to the associated risk with COVID-19 recovery, to psychosocial consequences such as low self-esteem. Habits pertaining to diet and exercise may affect a child's risk of becoming obese, with consumption of processed foods or a lack of physical exercise as risk factors. The objective of this study was to implement a school-based progam in two cities in the State of Chihuahua, Mexico, with the goal of preventing the development of childhood obesity through building life skills, gaining knowledge, and reducing psychosocial barriers to adopting a healthier lifestyle. Teachers were trained in workshops which prepared them to facilitate life skills, reduce psychosocial barriers and disseminate information through interactive activities with their fourth and fifth grade students, as well as engage in conferences with parents to review similar content regarding healthy practices. Results showed a statistically significant increase in the teacher's role as a health promoter in the classroom, compared with a no treatment group $\left(\mathrm{F}_{1,74}=4,302, \mathrm{p}=0.042, \eta^{2}=0.57\right)$, an increase in knowledge about diabetes and health care, as well as increased capability in taking care of their own diet $\left(F_{1,74}=6.103, p=0.006, \eta^{2}=0.937\right)$. Students' results in the treatment group showed a significant effect in knowledge about the healthy portion size of various types of food including the importance of daily consumption of vegetables $\left(\mathrm{F}_{1,1596}=4.033, \mathrm{p}=0.045\right)$, a significant decrease in consumption of junk food and sodas $\left(\mathrm{F}_{1,1593}=7.074, \mathrm{p}=0.008\right)$, and a significant decrease in drinking soda $\left(\mathrm{F}_{1,1593}=6.618\right.$, $\mathrm{p}=0.010$ ), compared with a no treatment group. Parents increased their knowledge of maintaining healthy eating habits and the importance of exercise as well as their self confidence to promote healthy habits in the family. These results demonstrate the success of the implementation of this comprehensive model based on life skills and intrinsic empowerment in encouraging behaviors as well as emotional and physical habits that reduce risk of childhood obesity, although long-term tracking of indicators such as body mass index (BMI) are needed to determine the efficacy of the program over an extended period of time.
\end{abstract}

Keywords: Obesity, Diabetes, School-Based Life Skills Program, Framework for Developing Empowerment (FrEE)

\section{Introduction}

\subsection{Background on Obesity}

Childhood obesity is a form of malnutrition that is growing globally, with over 40 million overweight children worldwide in 2019, an increase of 10 million individuals since 2000 [1]. Obesity, defined by the World Health Organization (WHO) as the abnormal or excessive accumulation of fat that poses a health risk, results when energy intake from meals is greater than a person's energy requirements $[1,2]$. Childhood obesity is especially salient as obese children are likely to remain 
obese as adults and are at risk of developing noncommunicable weight-related diseases, such as diabetes, at a relatively young age compared to their less heavy peers [3]. Habits and attitudes regarding the quality of food ingested and the meaning of being healthy have had an impact on increased numbers of children who are overweight and obese, with the consumption of processed foods, excessive portions, and a lack of physical exercise putting many adolescents at high risk of developing diabetes mellitus, cardiovascular disease, cancer, and other weightrelated illnesses, demonstrating the necessity of implementing comprehensive and effective prevention programs from an early age [4]. In addition to these physical health risks, obesity may lead to psychosocial consequences such as lower self-esteem, a higher likelihood of being bullied, poorer academic achievement, and poorer employment prospects as an adult, further demonstrating a need for prevention [5]. In addition, food and nutrition are influenced by a mix of biological and sociocultural aspects, with food playing a role in both humans' biological needs and social relations, so it is necessary that prevention programs take into account physiological, social, and family factors as well as address the strong influence of unhealthy consumption patterns [6].

\subsection{Obesity in Mexico}

Mexico is the OECD (Organization for Economic Cooperation and Development) country where diseases related to being overweight or obese will have the greatest impact on its GDP between 2020 and 2050, and the country has one of the highest rates of obesity in the OECD, with $34 \%$ of obese individuals identified as morbidly obese - the highest level of obesity [7]. The rate of child obesity in Mexico has doubled from $7.5 \%$ in 1996 to $15 \%$ in 2016 [7]. According to projections, diseases related to being overweight will reduce life expectancy in Mexico by more than four years over the next 30 years, the largest projected reduction among OECD countries [7]. The high level of overweight and obese individuals will effect Mexico's economic performance, with estimates finding that Mexico's labor force will be reduced by the equivalent of 2.4 million full-time workers per year, as people who are overweight and suffer from related conditions are less likely to be employed and, if employed, tend to be less productive. Further analysis found that being overweight and its associated illnesses are estimated to account for around $8.9 \%$ of health expenditure in Mexico per year between 2020 and 2050, and curb Mexico's GDP by an estimated $5.3 \%$ [7]. $28.90 \%$ of the Mexican population was considered obese in 2016, with $9.8 \%$ of children under five years of age considered obese in 2012 [8,9]. Given that children who are obese are more likely to be obese as adults than children who are not obese, preventive efforts against childhood obesity in Mexico could save the Mexican economy up to Mex\$110 billion each year for the treatment of diabetes, hypertension, and related noncommunicable illnesses by $2050[3,10]$. Comorbidities associated with obesity claim the lives of $28 \%$ of Mexicans each year [11].
The relatively high rate of obesity in Mexico may be correlated with its rapid increase in wealth in recent decades and the resulting population shifts from rural to urban setting: these changes increase access to energydense food at low prices and also encourage a more sedentary lifestyle [12].

Diabetes in particular is an ever-growing public health issue and the second highest cause of death for individuals (14\% overall) in Mexico, only after cardiovascular diseases [13]. According to the WHO, Mexico has one of the highest prevalence rates of diabetes in the world and is currently ranked as ninth globally for number of individuals with diabetes; it is estimated that by 2025 Mexico will be seventh globally and first in Latin America [14]. The National Survey on Health and Nutrition (ENSANUT) shows that 6.4 million (9.4\%) Mexicans over 20 years of age are aware they have diabetes [15]. In Chihuahua, diabetes prevalence is $6.3 \%$ with diabetes mellitus as the third most common cause of death in the state [16].

Data from ENSANUT show that diabetes mellitus, confirmed by medical diagnosis, increased from $5.8 \%$ in 2000 to $7.0 \%$ in 2006 to $9.2 \%$ in 2012 [15]. Around $15 \%$ of the current health expenditure is used for diabetes treatment [17]. This shows how diabetes is not only a severe public health issue, but additionally has important economic implications that will greatly affect Mexico in the future, especially if nothing is done to prevent it.

Chihuahua occupies the first place in childhood obesity at the national level: $11.4 \%$ of children under 5 years of age, $30 \%$ of children aged 5 to 11 , and $31 \%$ of adolescents are overweight or obese [16]. In Mexico, habits and attitudes regarding quality of food intake and what it means to be healthy have influenced the increase in the rate of obese and overweight children. Mexico's citizens consume more gallons of sugary beverages than any other country in the world; according to data from the National Institute of Statistics and Geography (INEGI), on average a Mexican family allocates $10 \%$ of its total income for purchasing soft drinks. This is concerning when considering that this type of drink can damage one's health, and as a caloric drink it can replace the consumption of other foods that are healthy [18].

Because of this and other cultural influences, there have been nutritional shifts in the Mexican diet, most noticeably among the poor. In fact, over the past 14 years, purchases of fresh fruits and vegetables have dropped nearly $30 \%$, while purchases of processed foods have increased almost $6 \%$ [19]. These cultural influences are also affecting the indigenous peoples of Mexico. Studies suggest that indigenous individuals can be genetically more susceptible to diseases that affect metabolism than other populations in Mexico, but traditionally their diet has protected them against diabetes mellitus and cardiovascular diseases. However, due to cultural influences and structural changes, many indigenous peoples have abandoned their traditional diet and started to consume more fat and sugar [20].

In addition to changes in the nutritional habits in both 
indigenous and other populations, a lack of adequate exercise causes weight and health problems. In Chihuahua, 37.2\% of adolescents and $24.4 \%$ of adults in the state are inactive or only moderately active [15]. Mexican authorities are aware of the fact that obesity and diabetes are posing a health challenge to the country not only with respect to medical and health aspects, but also in the way in which they affect school performance and labor activity among citizens. There has been a National Strategy for the Prevention and Control of Overweight, Obesity and Diabetes, which was launched by public, social, and private sectors to improve, promote, and restore the health and quality of life of Mexican families. This national strategy is composed of three main components: public health, timely medical care, and health regulation and tax policy. Within the public health component, the federal strategy sought to promote healthy lifestyles, health through education, and the implementation of preventive actions. Proposed regulations include policies on food and beverages in schools, food labeling, marketing of foods and non-alcoholic beverages to children, and fiscal measures [21]. However, changes in behaviors are needed to improve knowledge and promote life skills to encourage responsible decision making regarding healthy nutrition.

In this context, Yo quiero Yo puedo (IMIFAP), a Mexican NGO, proposed to implement a school-based life skills program to prevent childhood obesity and diabetes in the northern state of Chihuahua. The program "I want to, I can... improve child nutrition and prevent diabetes," developed a strategy of school-based health promotion through participatory workshops to implement a comprehensive program with the participation of parents, teachers, and children. It is well known that the development of life skills has been a pillar of numerous health education programs worldwide, since - among other things - they contribute to the prevention of health problems, functioning as a protective factor for various risk behaviors in populations of all ages and contexts, including harmful eating habits, and promoting the adoption of healthy behaviors that eventually become healthy lifestyles [22]. The program was based on the Framework for Developing Empowerment (FrEE), which postulated that the development of life skills, along with the reduction of psychosocial barriers and the acquisition of specific knowledge, lays the foundation for a change of attitudes and behaviors that result in people having greater control over their life in general and their health in particular. These changes specifically strengthened the personal agency and the intrinsic empowerment of people [23].

\subsection{Objectives of the Study}

1) To evaluate the effect of the program on teachers' healthy habits and on their role as health promoters.

2) To evaluate the effect of the program on $5^{\text {th }}$ grade students' knowledge and behaviors to prevent obesity and diabetes.

3) To assess parents' attitudes and self-efficacy towards healthy habits.

\section{Methods}

\subsection{Rationale and Design Process}

It has been demonstrated that preventive health programs based on the development of life skills and intrinsic empowerment are more effective than those that only disseminate health information [24].

The program, titled "I want to, I can... improve child nutrition and prevent diabetes," was school-based focusing on life skills and sought to raise awareness among children, teachers, and parents about the risks of being overweight and the relationship between obesity and noncommunicable diseases such as diabetes. During the previous phase of the implementation and evaluation, the program was designed with specific content for children, teachers, and parents to develop life skills, improve knowledge, reduce psychosocial barriers to change, and create new protective behaviors. Evaluation instruments were designed and piloted, as well as advocacy activities undertaken with school authorities and parents. The systematic evaluation of the impact of the program, reported in this study, was carried out during the second year of the implementation with the participants described in the following section.

\subsection{Participants}

30 schools were randomly assigned by local educational authorities to a treatment (12) or no treatment (18) group in the cities of Chihuahua and Ciudad Juarez in the Mexican State of Chihuahua.

Teacher $(\mathrm{N}=81)$ participants: 60 teachers were in the treatment group, $71.78 \%$ of which were female and $28.3 \%$ male, with an average age of 35 years. 21 teachers participated in the no treatment group, $81 \%$ of which were female and $19 \%$ male, with an average age of 38.3 years.

$5^{\text {th }}$ grade student $(\mathrm{N}=1603)$ participants: 918 students were in the treatment group (48\% boys and 52\% girls, with an average age of 10.25 years) and 685 students participated in the no treatment group $(52.1 \%$ girls and $47.9 \%$ boys, with an average age of 10.31 years).

Parent $(\mathrm{N}=85)$ participants from the treatment schools: Parent participants were $90.6 \%$ female and $9.4 \%$ male and ranged from 26 to 57 years of age with an average age of 38.3 years. Parents had an average of 2.6 children, ranging from 1 to 7 .

\subsection{Program Content}

The program for teachers included four main areas (life skills, healthy nutrition and prevention of obesity, physical activity, and diseases related to overweight and obesity). The contents were designed to be taught in participatory and play-based sessions (Table 1). Twenty lessons were designed for $5^{\text {th }}$ grade students, supported with a workbook and a storybook. Lessons for children included knowledge and life skills, such as selfknowledge, expression of feelings, assertive communication, and decision making, relevant to healthy behaviors (Table 2). 
Table 1. Content of teacher training "I want to, I can ... improve child nutrition and prevent diabetes" program [25].

\begin{tabular}{ll}
\hline Theme & Topic \\
\hline Life Skills & Management of emotions \\
& Management of stress \\
& Assertive communication \\
Critical thinking & Decision making \\
& Health and nutrition \\
& Self-knowledge \\
Healthy Nutrition and Prevention of Obesity & Food groups \\
& "El Plato del Bien Comer" (balanced plate) \\
& Reading labels \\
& Health risks of obesity \\
& Technique for measuring weight and height \\
Physical Activity & Technique for measuring waist and hip circumferences \\
Diseases related to being overweight or obese & Body Mass Index (BMI) \\
\hline
\end{tabular}

Table 2. Content of lessons for students in the "I want to, I can ... improve child nutrition and prevent diabetes" program [26, 27].

\begin{tabular}{|c|c|}
\hline Lesson \# & Content Covered (lesson name and area) \\
\hline 1. & I know and take care of myself - Self knowledge \\
\hline 2. & I like the way I am - Self acceptance \\
\hline 3. & I have my own abilities - Talent development \\
\hline 4. & I manage my feelings - Expression of feelings \\
\hline 5. & I talk to myself - Internal communication of needs \\
\hline 6. & I identify my emotions - Anxiety management \\
\hline 8. & I know how to handle frustration - Problem resolution \\
\hline 9. & I set limits - Assertive communication \\
\hline 10. & I am an agent of change - Leadership \\
\hline 11. & I know how much I weigh and my height - Self monitoring \\
\hline 12. & I know "El Plato del Bien Comer" (balanced plate) - Knowledge \\
\hline 13. & I try new foods - Experimentation and creativity \\
\hline 15. & I know the hormones of my body - Knowledge and self-acceptance of changes \\
\hline 16. & I decide what I eat - Decision making \\
\hline 17. & I learn about portion sizes - Knowledge \\
\hline 18. & I drink water to be healthy - Knowledge \\
\hline 19. & I like to exercise - Attitudes toward exercise \\
\hline 20. & My body is healthy! - Attitudes toward healthy life \\
\hline
\end{tabular}

\subsection{Design and Implementation}

The program was presented to the Ministry of Health and Ministry of Education in the State of Chihuahua, Mexico. One working session and 4 conferences were carried out to select the schools and coordinate the implementation. 187 elementary schools were identified to participate in the study. Schools were assigned randomly to a control or treatment group. Teachers in the treatment group participated in a $25-$ hour workshop guided by a trained facilitator. Once the workshop was completed, each participating teacher implemented the program with their group of students during the school year. All teachers received two accompaniment visits spaced two weeks apart, during which they received feedback to reinforce and complement their work replicating the program. Accompaniment visits were carried out by facilitators who recorded teachers' level of empowerment and personal agency during the delivery of the program. Parents attended two interactive conferences during the school year and received a recipe book [28] with healthy recipes relevant for all family members. Teachers, parents, and children in the no treatment group received the regular curriculum of the school year.

\subsection{Evaluation Design and Instruments}

Students and teachers were evaluated by self-reported questionnaires, previously piloted, using a pre-post design with a control (no treatment) group. Teacher questionnaires consisted of 78 closed questions assessing four areas: life skills, knowledge, attitudes, and behaviors regarding healthy habits and three open questions to explore their satisfaction with the program. Student questionnaires consisted of 58 closed questions to explore knowledge, attitudes, and the application of life skills in behaviors regarding healthy 
nutrition habits and physical exercise. Parents were evaluated after the second interactive conference, using an exit poll containing 19 closed questions exploring attitudes and selfefficacy toward healthy eating and physical exercise, while seven open questions explored their satisfaction with the program. During accompaniment visits, facilitators rated teachers' personal agency, using a score from 1 to 10 .

\subsection{Statistical Analysis}

Analysis of variance (ANOVA) with two measurements and two groups was used for the evaluation of the program. $X^{2}$ was used for nominal data. Parent evaluations were recoded into performance scores ranging from 0 (poor) to 100 (excellent), considering low performance from 0 to 59 points, medium performance from 60 to 79 points, and high performance 80 points and above.

\section{Results}

\subsection{Teachers}

\section{Healthy habits and role as health promoters}

Teachers in the treatment group showed an increase in their role as a health promoter in the classroom compared

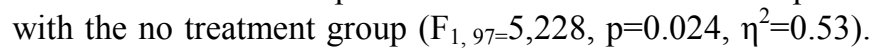
ANOVA results showed a significant interaction $\left(F_{1}\right.$, 74) $=4.302, p=.042, \eta^{2}=.057$ ) between group and time (Figure 1). On healthy nutrition habits, teachers in the treatment group consumed significantly more amounts of fruits and vegetables and drank less soda than the no treatment group, replacing their choice of drink with simple water $\left(X^{2}=10,647.1, \quad \mathrm{p}=0.001\right)$. Percentage of healthy habits changed from $53.3 \%$ to $94.7 \%$ in the treatment group vs. $45.5 \%$ to $61.5 \%$ in the no treatment group. No differences were found between groups in attitudes on physical exercise. Group effects were also found in the perception that healthy food is not expensive $\left(\mathrm{F}_{1,74}=6.103, \mathrm{p}=0.006, \eta^{2}=.937\right)$ (Table 3).

Acceptance and satisfaction with the program in the treatment group

Most teachers (95.6\%) reported feeling "very or completely satisfied" with their participation. $100 \%$ of the teachers reported that they "would participate in a similar program", and $86.7 \%$ of the teachers demonstrated satisfactory levels of empowerment and personal agency registered by the facilitators in the accompaniment visits.

Table 3. Mean scores $(M)$ and standard deviations (SD) for treatment and no-treatment group on pre-test, post-test and follow up measurements.

\begin{tabular}{lllll}
\hline & Time 1 & \multicolumn{3}{c}{ Time 2 } \\
\cline { 2 - 5 } & M & SD & M & SD \\
\hline Teacher's role as a health promoter & & & & \\
Treatment group & 76.9 & 17.7 & 88.07 & 11.45 \\
$\begin{array}{l}\text { No treatment group } \\
\text { Physical exercise is not boring }\end{array}$ & 90.3 & 15.5 & 82.00 & 19.38 \\
Treatment group & & & & \\
No treatment group & 91.11 & 18.27 & 84.21 & 25.74 \\
Healthy food is not expensive & 93.93 & 13.48 & 86.67 & 32.20 \\
Treatment group & & & & \\
No treatment group & 49.44 & 30.37 & 66.67 & 31.42 \\
\hline
\end{tabular}

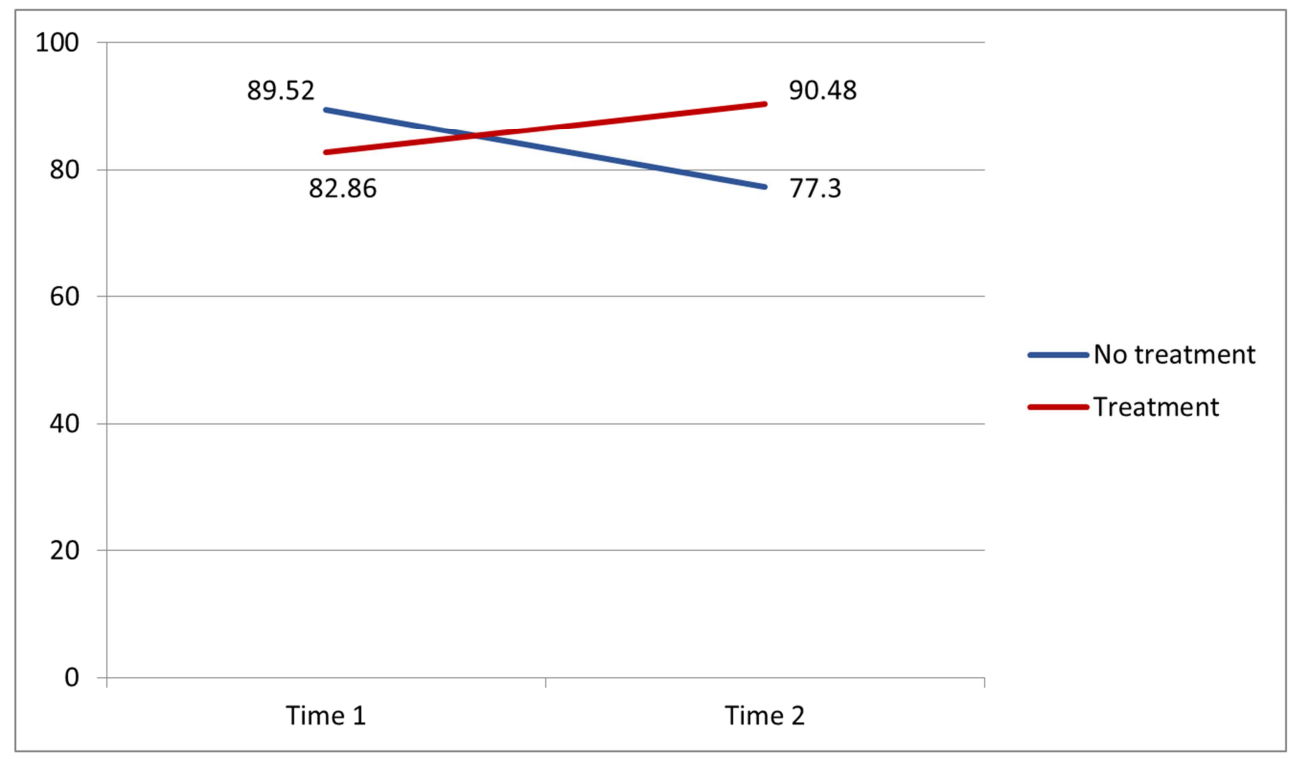

Figure 1. Mean scores for the role of teachers as health promotor by time and group.

\subsection{Students}

Results showed a significant effect in children's knowledge on the healthy portion size of different types of food, including the importance of daily consumption of vegetables $\left(\mathrm{F}_{1,1596}=4.033, \mathrm{p}=0.045\right)$ (Table 4 and Figure 2).
Results also showed a significant decrease in consumption of junk food and sodas $\left(\mathrm{F}_{1,1593}=7.074, \mathrm{p}=0.008\right)$. A significant decrease in drinking soda was observed in the treatment group $\left(\mathrm{F}_{1,1593}=6.618, \mathrm{p}=0.010\right)$. This result was confirmed by a significant increase in drinking plain water, from $60.8 \%$ to $70.0 \%$ in the treatment group, compared to from $68.9 \%$ to 
$72.6 \%$ for the no treatment group $\left(\mathrm{X}^{2}=8.532, \mathrm{p}=0.001\right)$.

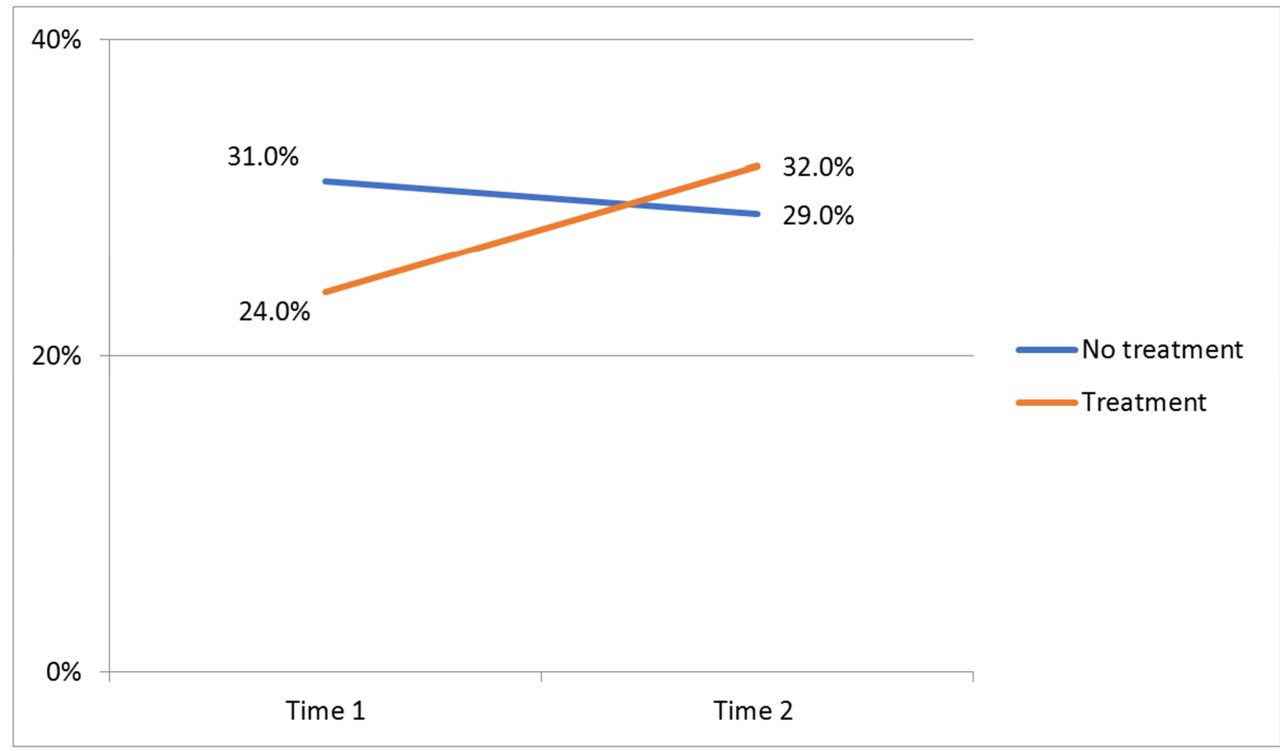

Figure 2. Mean scores for $5^{\text {th }}$ grade students' knowledge about portion size by time and group.

Table 4. Mean scores (M) and standard deviations (SD) for treatment and no-treatment group on pre-test measurements in students.

\begin{tabular}{lllll}
\hline & Time1 & \multicolumn{3}{c}{ Time 2 } \\
\cline { 2 - 5 } & M & SD & M & SD \\
\hline $\begin{array}{lllll}\text { Knowledge about size of portion } \\
\text { Treatment group }\end{array}$ & 24.00 & 4.29 & 32.00 & 4.65 \\
$\begin{array}{l}\text { No treatment group } \\
\text { Drinking soda }\end{array}$ & 31.00 & 4.64 & 29.00 & 4.55 \\
$\quad$ & & & \\
Treatment group & 42.2 & 3.63 & 40.6 & 6.12 \\
No treatment group & 39.9 & 7.29 & 45.2 & 5.22 \\
$\begin{array}{l}\text { Daily ingestion of vegetables } \\
\text { Treatment group }\end{array}$ & 47.5 & 0.76 & 48.8 & 3.42 \\
$\quad$ No treatment group & 54.1 & 3.29 & 48.8 & 3.06 \\
Consumption of junk food & & & & \\
$\begin{array}{l}\text { Treatment group } \\
\text { No treatment group }\end{array}$ & 41.2 & 1.96 & 39.6 & 4.19 \\
\hline
\end{tabular}

\subsection{Parents}

Parents in the treatment group demonstrated high scores, in a range from $0-100$, on attitudes and self-efficacy to facilitate healthy nutrition and physical exercise in their family members. Parents obtained the lowest score on selfefficacy toward their own diet (Table 5). Parents in the no treatment group did not receive any conference since that is not included in the regular curriculum.

Table 5. Mean scores (M) and standard deviations (SD) for treatment group in exit poll measurement for parents.

\begin{tabular}{lcc}
\hline & \multicolumn{2}{c}{ Time 2 } \\
\cline { 2 - 3 } & M & SD \\
\hline $\begin{array}{l}\text { Attitudes towards healthy eating } \\
\text { Treatment group }\end{array}$ & 90.37 & 14.02 \\
$\begin{array}{l}\text { Attitudes towards physical activity } \\
\text { Treatment group }\end{array}$ & & \\
$\begin{array}{l}\text { Attitudes towards diabetes prevention } \\
\text { Treatment group }\end{array}$ & 83.98 & 15.24 \\
$\begin{array}{l}\text { Self-efficacy towards own healthy eating* } \\
\text { Treatment group }\end{array}$ & 88.89 & 18.40 \\
\hline
\end{tabular}

\begin{tabular}{|c|c|c|}
\hline & \multicolumn{2}{|c|}{ Time 2} \\
\hline & $\mathbf{M}$ & SD \\
\hline $\begin{array}{l}\text { Self-efficacy towards healthy eating for children } \\
\text { Treatment group }\end{array}$ & 96.78 & 9.88 \\
\hline $\begin{array}{l}\text { Self-efficacy towards own physical activity } \\
\text { Treatment group } \\
\text { Self-efficacy towards nhysical activity for children }\end{array}$ & 82.24 & 19.03 \\
\hline Treatment group & 94.30 & 12.61 \\
\hline
\end{tabular}

\section{Discussion}

Both knowledge and comprehension of nutrition, healthy eating habits, maintaining a balanced diet, body awareness in relation to food, physical exercise, and risks and diseases associated with obesity were increased in students who participated in the program. Further, students demonstrated an increase in healthy eating habits such as consuming fewer unhealthy snacks between meals and drinking more plain water. These results demonstrate the relevance of including life skills as a core component of the program. In particular, participatory methodology applied during the school year allowed students to better handle situations including cultural beliefs about rejecting food at social events, social pressure, and critical thinking to analyze marketing messages about "junk food". The focus of the program did not include the total elimination of certain foods, but rather the knowledge and responsibility to balance a diet and the promotion of physical exercise.

After the program concluded, parents felt highly prepared to motivate their children to adopt healthier eating habits and exercise routines, indicating an increased level of selfefficacy, and felt that the parent conferences and materials, such as the recipe book provided, gave them tools to have healthier habits and prevent diabetes. However, they felt less prepared to improve their own diets. This result demonstrated that parents need more than interactive conferences to be able 
to change self-care behaviors, with parents potentially feeling cultural pressure to invest more effort in taking care of their children and family than in their own emotional and physical health.

The results of the study further demonstrate a decrease in perceived psychosocial barriers for participants and a favorable change in attitudes and social norms regarding best practices for nutrition, healthy eating, and living a healthy lifestyle, and for reducing obesity and diabetes. Given the fact that habits and behaviors regarding food intake, exercise, and the meaning of health in general affect the number of children with obesity, programs similar to the one implemented in this study may have a positive effect in reducing childhood obesity [4]. With the potential of reducing childhood obesity, this program could ameliorate noncommunicable obesity-related diseases such as diabetes or hypertension as well as negative psychosocial impacts such as low self-esteem $[4,5]$. As children who are obese are more likely to be obese as adults, preventive programs such as this may have positive consequences lasting decades [3].

In an analysis of nineteen studies on school-based interventions for childhood obesity, programs lasting one or more years were found to be more effective than control groups in decreasing the number of participants who became overweight or obese; no difference was found in programs lasting less than six months [29]. There was a decrease in body mass index (BMI) for school-based interventions with a duration of between one and two years compared to control groups, with no difference in BMI between experimental and control groups for studies lasting less than one year or greater than two years [29]. Long-term follow ups between one and 10 years found students who participated in these programs had a greater reduction in BMI compared to students who participated in control groups [29]. These results from previous research suggest the efficacy of school-based interventions such as the program implemented in this study in developing positive long-term effects related to establishing a healthy weight in students, with long-term interventions demonstrating greater success than shorter interventions.

The results of this study demonstrate that school-based interventions focusing on preventing childhood obesity need to include components on life skills and the reduction of psychosocial barriers, considering the cultural context and involvement of parents and teachers. It is important to increase the knowledge of students, teachers, and parents about healthy behaviors regarding diet and exercise, however, it is equally important to promote critical thinking and decision making in order to maintain healthy behaviors and increase the self-efficacy of teachers and parents in disseminating this knowledge to their students and children, respectively. Although there are no data for the long-term impacts of this program, previous studies on similar schoolbased interventions found programs were effective in decreasing the BMI of participants as well as the number of students who became overweight or obese compared to control groups [29]. Next steps for this research include expanding the program beyond fourth and fifth grades to all academic years and collecting height and weight data on participants to calculate BMI and measure the long-term efficacy of the program. While the results of this study indicate increased competence of participants regarding healthy eating and exercise habits, the long-term effects of the program on their physical health have not yet been studied.

\section{Conclusions}

The program "I want to, I can... improve child nutrition and prevent diabetes" was successful in its goal of training teachers and involving parents to implement a comprehensive model based on life skills and intrinsic empowerment to encourage behaviors as well as emotional and physical habits that reduced risk of childhood obesity, directly addressing this growing form of malnutrition and its associated range of physical and psychosocial ailments [1]. Students, teachers, and parents involved in the project all demonstrated an increased ability to improve healthy habits relating to diet and exercise, and teachers and parents showed an increased ability to promote healthy behaviors in others, such as their students and children, respectively. Teachers specifically were successful in both their ability to disseminate critical health information to students and their ability to positively change their personal health as a first step in acting as a role model for their students.

The program's implementation strategy met the requirements of the Ministry of Education and Sports of the Government of the State of Chihuahua, Mexico to be implemented as a school based program opening the possibility of expanding it to other school grades and other regions to start a process of scaling up. The program was based on the Framework for Developing Empowerment (FrEE), which postulated that the development of life skills, along with the reduction of psychosocial barriers and the specific knowledge, leads to a change of attitudes and behaviors that result in people having greater control over their life and their health in particular. These changes specifically strengthened the personal agency and the intrinsic empowerment of people, so that sustainable changes were achieved at the individual, family, and community level [23]. In addition to its strong methodological basis, similar studies on school-based childhood obesity prevention programs indicate the long-term efficacy of comparable interventions, although the long-term impact of this particular study and the FrEE methodology has yet to be investigated [29].

\section{Conflict of Interest and Founding}

The authors declare that they have no competing interest.

\section{Acknowledgements}

We want to express our gratitude to World Diabetes 
Foundation (WDF 14-939 Mexico), to the educational authorities of the Ministry of Education and Sports of the Government of the State of Chihuahua, to children, teachers, and parents of the participating schools in the State of Chihuahua and IDEAME (Grant MB1411) for their support for the implementation of this program.

\section{References}

[1] World Health Organization. (2019). Levels and trends in child malnutrition: key findings of the 2019 edition (No. WHO/NMH/NHD/19.20). World Health Organization.

[2] World Health Organization. (2000). Obesity: preventing and managing the global epidemic (No. 894). World Health Organization.

[3] Sahoo, K., Sahoo, B., Choudhury, A. K., Sofi, N. Y., Kumar, R. \& Bhadoria, A. S. (2015). Childhood obesity: causes and consequences. Journal of family medicine and primary care, 4 (2), 187.

[4] Hurt, R. T., Kulisek, C., Buchanan, L. A. \& Mc Clave, S. A. (2010). The obesity epidemic: challenges, health initiatives, and implications for gastroenterologists. Gastroenterology \& hepatology, 6 (12), 780.

[5] World Health Organization. (2018). Taking action on childhood obesity (No. WHO/NMH/PND/ECHO/18.1). World Health Organization.

[6] Nordström, K., Coff, C., Jönsson, H., Nordenfelt, L. \& Görman, U. (2013). Food and health: individual, cultural, or scientific matters? Genes \& nutrition, 8 (4), 357-363.

[7] Organization for Economic Co-operation and Development (OCDE). (2019). The heavy burden of obesity: the economics of prevention. Heath Policy Studies. https://www.oecd.org/about/secretary-general/heavy-burdenof-obesity-mexico-january-2020.htm

[8] Central Intelligence Agency. (n.d.). Country comparison: obesity-adult prevalence rate. Retrieved at: https://www.cia.gov/library/publications/the-worldfactbook/rankorder/2228rank.html. June 03, 2020.

[9] Aceves-Martins, M., Llauradó, E., Tarro, L., Solà, R. \& Giralt, M. (2016). Obesity-promoting factors in Mexican children and adolescents: challenges and opportunities. Global health action, 9 (1), 29625.

[10] Garduño-Espinosa, J., Morales-Cisneros, G., MartínezValverde, S., Contreras-Hernández, I., Flores-Huerta, S., Granados-García, V. \& Muñoz-Hernández, O. (2008). A look from health services to the nutrition of Mexican children. III. Economic and health burden of obesity in Mexican children. Long-term projections. Boletín médico del Hospital Infantil de México, 65 (1), 49-56.

[11] Gómez, A. (2015). 170 thousand die of obesity each year. http://www. eluniversal. com. mx/articulo/periodismodeinvestigacion/2015/07/14/mueren-por-obesidad-al-ano-170-mil.

[12] Rtveladze, K., Marsh, T., Barquera, S., Romero, L. M. S., Levy, D., Melendez, G... \& Brown, M. (2014). Obesity prevalence in Mexico: impact on health and economic burden. Public health nutrition, 17 (1), 233-239.
[13] World Health Organization. (2016). Country profiles for diabetes.

https://www.who.int/diabetes/countryprofiles/mex es.pdf?ua=1.

[14] Andrade Cetto, A. (2019). Mexico ranks 9th in the world in diabetes. Bulletin UNAM-DGCS-305. University City. May 4, 2019.

https://www.dgcs.unam.mx/boletin/bdboletin/2019_305.html\# $: \sim:$ text $=$ Es $\% 20$ un $\% 20$ problema $\% 20 \mathrm{de} \% 20$ salud,cerca $\% 20 \mathrm{de}$ $\% 2012 \% 20$ millones\%2C\%20refiri\%C3\%B3.

[15] ENSANUT. (2012). National survey of health and nutrition, results by state. National Institute of Public Health. Health Secretary. Chihuahua. Retrieved on October 19, 2018. https://ensanut.insp.mx/informes/Chihuahua-OCT.pdf.

[16] Rojas-Martínez R, Basto-Abreu A, Aguilar-Salinas C.A., Zárate-Rojas E, Villalpando S. \& Barrientos-Gutiérrez T. (2018). Prevalence of diabetes due to previous medical diagnosis in Mexico. Salud Publica Mex.; 60: 224-232. https://doi.org/10.21149/8566.

[17] Federación Mexicana de Diabetes (2015). Ministry of Heath spends 15 percent of its budget on diabetes care. Retrieved from http://fmdiabetes.org/presupuesto-atencion-diabetesgasta-15-presupuesto-salud/. July 27, 2020.

[18] Hernández Villarreal M.O., Ramos Peña E. \& Núñez Rocha G. (2015). Practices and advertising in the consumption of soft drinks in Mexicans. Revista de Salud Pública y Nutrición / Vol. 14, No. 1, January-March.

[19] Gaona-Pineda E, Martínez-Tapia B, Arango-Angarita A, Valenzuela-Bravo D, Gómez-Acosta LM, Shamah-Levy T. \& Rodríguez-Ramírez S. (2018). Consumption of food groups and sociodemographic factors in the Mexican population. Salud Publica Mex, 60: 272-282.

[20] Alvarado-Osuna C, Milian-Suazo F. \& Valles-Sánchez V. (2001), Prevalence of diabetes mellitus and hyperlipidemias in indigenous Otomi. Salud Publica Mex, 43, 459-463.

[21] Secretaría de Salud. (2013). National strategy for the prevention and control of overweight, obesity and diabetes. Retrieved on July 27, 2020. http://www.cenaprece.salud.gob.mx/descargas/pdf/EstrategiaN acionalSobrepeso.pdf.

[22] World Health Organization. (1999). Partners in Life Skills Education. Conclusions from a United Nations Inter-Agency Meeting. Department of Mental Health. Ginebra: WHO. http://www.who.int/mental health/media/in/30.pdf.

[23] Pick, S. \& Sirkin, J. (2010). Breaking the poverty cycle: The human basis for sustainable development. Oxford University Press, USA.

[24] Pick, S., Venguer, T. \& Fishbein, M. (2007). Health education and agency: a comprehensive program for young women in the Mixteca region of Mexico. Psychology, Health \& Medicine Journal, 12 (4), 389-406.

[25] Givaudan, M., Jiménez, D., Barriga, M. \& Elizalde, L. (2017). I want to, I can... improve children's nutrition and prevent diabetes. Teachers' manual. Idéame: Mexico.

[26] Givaudan, M., Barriga, M. \& Elizalde, L. (2018). I want to, I can... improve children's nutrition and prevent diabetes. Children workbook. Idéame: Mexico. 
[27] Givaudan, M. \& Castellanos, D. (2015). Chucho and Eva learn about diabetes (children's story). Idéame: Mexico.

[28] García, C. \& Castellanos, D. (2018). I want to, I can... improve children's nutrition and prevent diabetes (weekly menus for preschool and school-age children). Idéame: Mexico.
[29] Gonzalez-Suarez, C., Worley, A., Grimmer-Somers, K. \& Dones, V. (2009). School-based interventions on childhood obesity: a meta-analysis. American journal of preventive medicine, 37 (5), 418-427. 